\title{
LEARNER-GENERATED DIGITAL MEDIA (LGDM) FRAMEWORK
}

\author{
J. Reyna', P. Meier', J. Hanham², P. Vlachopoulos ${ }^{3}$, K. Rodgers ${ }^{1}$ \\ ${ }^{1}$ University of Technology Sydney (AUSTRALIA) \\ ${ }^{2}$ Western Sydney University (AUSTRALIA) \\ ${ }^{3}$ Macquarie University (AUSTRALIA) \\ jorge.reyna@uts.edu.au
}

\begin{abstract}
Learner-Generated Digital Media (LGDM) has been incorporated as a tool to assess students in K-12 and higher education in the last decade. There are frameworks developed for video making in the classroom that considers technical know-how and a model that incorporate pedagogies. However, there is the absence of a practical framework to inform academics and students on the implementation of digital presentations as an assessment tool in the curricula. The aim of this poster is to propose a model for how to design, implement and evaluate LGDM as assessment tools in tertiary education. This evidence-based framework considers the following elements: (1) pedagogy; (2) student training; (3) hosting of videos; (4) marking schemes; (5) group contribution; (6) feedback; (7) reflection, and; (8) evaluation. The model servers as a conduit between theory and good practice.
\end{abstract}

Keywords: learner-generated digital presentations, storytelling, video as assessment items, digital media, digital media literacy, digital media as an assessment tool.

\section{INTRODUCTION}

Learner-Generated Digital Media (LGDM) emerged more than a decade ago in the field of education [1] and had been incorporated recently into other disciplines such as science [2, 3]. Learner-generated content provides opportunities to improve students' skills such as problem-solving, cooperative learning, critical thinking, and motivation [4]. Other skills include the development of different types of literacies such as digital, technological, visual and global [5]. Teachers are using these technologies as valuable tools for motivation, collaboration, expression, and authentic assessment [6]. Additionally, LGDM has been identified as having the potential to add value in hands-on experience but also through peer-driven learning [7].

In education, the use of LGDM has focused on the reflection of pre-service teaching experiences [8], rather than active learning, creativity, inquiry and research approaches. Nevertheless, research on LGDM in higher education is considered to be under-theorised and barely sufficient [9], there is a need for rigorous studies to evaluate how students learn with LGDM in diverse disciplines [10]. A gap in the literature has been identified, a practical model to guide academics and students on the implementation of LGDM as an assessment tool has not been proposed.

\section{AIMS}

The aims of this research proposal are: (1) to develop and refine a theoretical framework to guide the implementation of digital presentations as assessment tools in tertiary learning, and; (2) to gain an indepth understanding of how students learn through creating digital presentations.

\section{THE LGDM FRAMEWORK}

The LGDM model has eight elements starting from pedagogy and ending the cycle with an evaluation to inform future improvements (Figure 1). These elements were chosen based on experience working in educational technology helping academics to develop assessment tasks that use innovative tools. Elements of the model are briefly explained below and linked to a set of questions students will need to understand before undertaking the assessment. For academics, the model acts as a conduit between theory and good practice. From the student's perspective, the model informs how the assessment works. Communicating this information is to ensure students will buy into the task and have clear expectations of what will be required from them. 
Figure 1: The Learner-Generated Digital Media (LGDM) Framework. DMP stands for Digital Media Project.

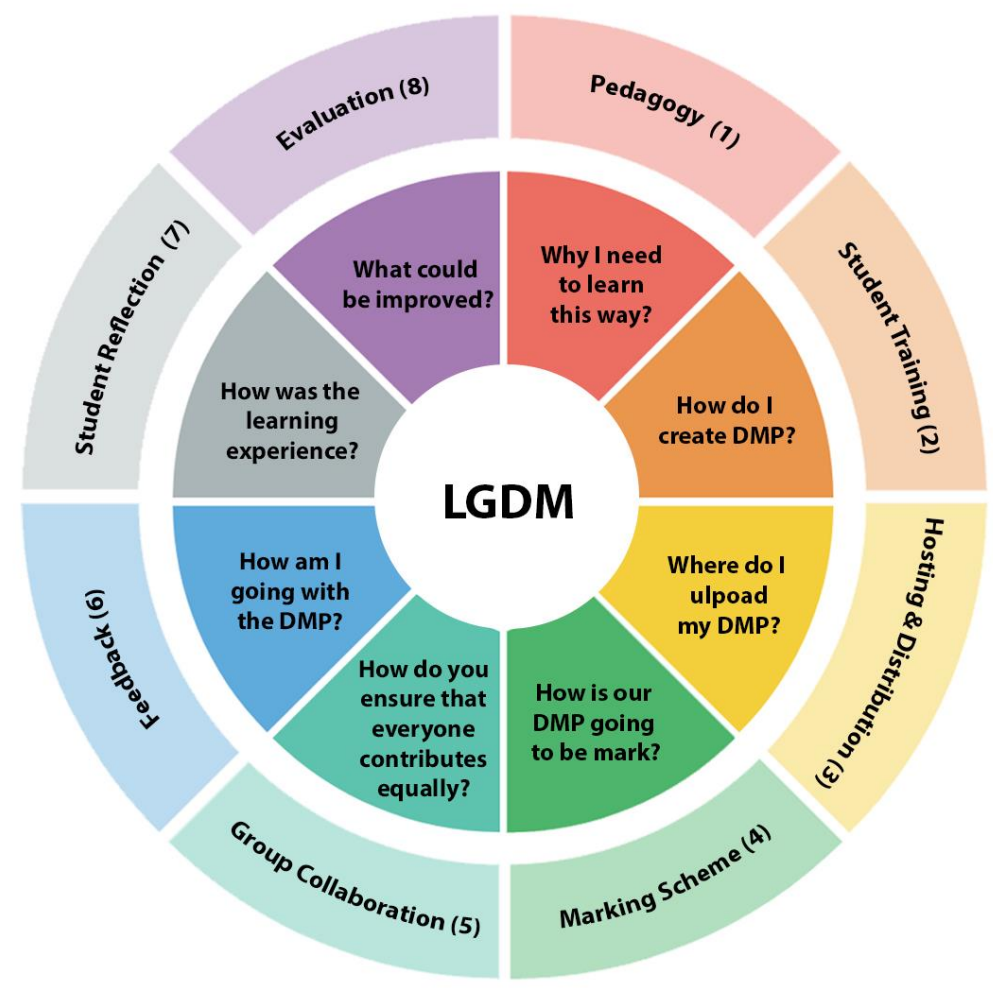

\subsection{Pedagogy}

Pedagogy is driven by active learning approaches, students working in small groups and 'learning by doing'. Some examples are Problem Based Learning [11]; Collaborative Learning [12], Cooperative Learning [13], Peer-Assisted Learning [14], and Case Studies [15]. These pedagogies can be used to design LGDM assessments as they seek students engaging with technology and develop research skills, collaborative working, problem-solving, technology and organisational skills [16]. When designing LGDM assessments, it is also important to ensure subject learning objectives are aligned with graduate attributes, and the digital media tasks the students will undertake [17]. This element will address the student's question: Why I need to learn this way? The framework begins with pedagogy as a separate entity but underpins each of the seven elements. The separation has been made for instructional proposes.

\subsection{Student training}

We identified that digital media support for students is essential. Training on how to create effective digital presentations needs to be planned and delivered to the students. Topics to be covered in this section are: (1) digital presentation types; (2) layout design; (3) colour theory; (4) typography; (5) use of images; (6) audio recording; (7) video quality and resolution; (8) video framing and shots; (9) storyboarding, and; (10) tools available to produce digital presentations [18]. Students will need to engage in a hands-on workshop to brainstorm their ideas with their peers and instructors and it is crucial for the instructor to provide feedback at this stage. This element will address the student's question: How do I create a digital media project?

\subsection{Hosting of video}

The video hosting service should be determined before designing the assessments. Digital presentation assignments should be accessible to all the students as it will foster discussion and consideration of ideas. The use of Web 2.0 tools to host videos such as YouTube and Vimeo can be taken into 
consideration [19]. Creating a classroom account in those services and sharing the details with the students will be well suited. Students should be able to see each group's work and comment if necessary. This element will address the student's question: Where do I upload my digital media project?

\subsection{Marking scheme}

It is important to determine the weighting of the activity since preparation of digital media projects can be time-consuming. It is recommended to have at least $20 \%$ of the total subject mark devoted to this assignment. Additionally, the use of rubrics is highly encouraged as it will help the students to focus on the important elements of the task and will make the marking more objective if several tutors/instructors are involved in the marking process [20]. As students are receiving training in digital media, the assignment should not only mark the content but the application of digital media principles. This element will address the student's question: How is our digital media project going to be marked?

\subsection{Group contribution}

Mechanisms to ensure all group members are contributing to the project need to be implemented. The best approach, in this case is self and peer-assessment [21, 22]. A contribution to group work rubric needs to be developed, and a peer review application used to allow students to rate each other's contribution to the project. Using such a tool helps to identify free riders and non-contributors. This element will address the student's question: How do you ensure that everyone contributes to the digital media project?

\subsection{Feedback}

When implementing learning designs that use innovative ways to assess students, it is critical to provide targeted, specific and timely feedback. The purpose of feedback aims to reduce discrepancies between understanding, performance and a goal [23]. In the case of a digital media project, students need feedback earlier on the storyboard, and then, on the tools they are planning to use. Later, feedback on the drafts is critical to reinforce student's learning on the content and the digital media principles. These levels of feedback will allow students to produce an effective digital artefact and minimise anxiety that the task could produce. This element will address the student's question: How are we going with the digital media project?

\subsection{Student reflection}

Research has shown that student's perceptions of the benefits of educational technology can be diminished. Not until analysing the data and comparing performance, can we elucidate the benefits of the intervention [24]. Adding a reflection task after the assignment will help the students to rethink if they have gained additional knowledge by engaging in the development of a digital media project. This task can be implemented using a reflective journal inside the LMS and by asking the students simple questions such as: what do you feel you learned from this task? How could you use the skills you developed? This element will address the student's question: How was the learning experience developing a digital media project?

\subsection{Evaluation}

Evaluation is an important part of any educational intervention. The purpose of evaluation is to produce data that will help to improve the activity in the next iteration. The process of evaluation involves (1) identifying the activity/task; (2) developing questions (for students and tutors); (3) determining the sources of data; (4) collection and analysis; (5) making the adjustments required, and; (6) starting again. Sources of data can be teacher reflection, student's perceptions (via survey and focus groups), student's assessment performance (grade attained) and student actions (group contribution) (Phillips \& Gilding, 2002). This element will address the student's question: What could be improved on the assignment?

\section{WORK IN PROGRESS}

We conducted a pilot study in 2016 that included five subjects (Pharmacology, Geology, Ecology, Traditional Chinese Medicine and Midwifery) at the Faculty of Science, University of Technology Sydney. The assessment design followed the LGDM framework and we captured student's attitude towards LGDM via an online survey, group work data using SPARKPlus peer review application and marks attained. We are currently analysing the data using methodological triangulation. So far students 
reported the task was engaging, they enjoyed group work and be creative, and they were optimistic about the assignment.

\section{REFERENCES}

[1] Kearney, M. and S. Schuck. Students in the director's seat: Teaching and learning with student-generated video. in Proceedings of Ed-Media 2005 World Conference on Educational Multimedia, Hypermedia and Telecommunications. 2005. Citeseer.

[2] Powell, L.M., Evaluating the Effectiveness of Self-Created Student Screencasts as a Tool to Increase Student Learning Outcomes in a Hands-On Computer Programming Course. Information Systems Education Journal, 2015. 13(5): p. 106.

[3] Stuckey, S.E., Examining The Impact Of Student-Generated Screencasts On Middle School Science Students'interactive Modeling Behaviors, Inquiry Learning, And Conceptual Development. 2012, Appalachian State University.

[4] Ohler, J.B., Digital storytelling in the classroom: New media pathways to literacy, learning, and creativity. 2013: Corwin Press.

[5] Robin, B.R., et al., Preparing for the changing role of instructional technologies in medical education. Academic Medicine, 2011. 86(4): p. 435-439.

[6] Hazzard, E., Screencasts are a valuable tool for motivation, collaboration, expression, and authentic assessment. The Science Teacher, 2014. 81(3).

[7] Berardi, V. and G.E. Blundell, A learning theory conceptual foundation for using capture technology in teaching. Information Systems Education Journal, 2014. 12(2): p. 64.

[8] Rich, P.J. and M. Hannafin, Video annotation tools technologies to scaffold, structure, and transform teacher reflection. Journal of Teacher Education, 2009. 60(1): p. 52-67.

[9] Hakkarainen, K., A knowledge-practice perspective on technology-mediated learning. International Journal of Computer-Supported Collaborative Learning, 2009. 4(2): p. 213-231.

[10] Duffy, T.M. and D.H. Jonassen, Constructivism and the technology of instruction: $A$ conversation. 2013: Routledge.

[11] Hmelo-Silver, C.E., Problem-based learning: What and how do students learn? Educational psychology review, 2004. 16(3): p. 235-266.

[12] Goodsell, A.S., Collaborative learning: A sourcebook for higher education. 1992.

[13] Millis, B.J. and P.G. Cottell Jr, Cooperative Learning for Higher Education Faculty. Series on Higher Education. 1997: ERIC.

[14] Topping, K. and S. Ehly, Peer-assisted learning. 1998: Routledge.

[15] McDade, S.A., Case study pedagogy to advance critical thinking. Teaching of psychology, 1995. 22(1): p. 9-10.

[16] Malita, L. and C. Martin, Digital storytelling as web passport to success in the 21st century. Procedia-Social and Behavioral Sciences, 2010. 2(2): p. 3060-3064.

[17] Biggs, J.B., Teaching for quality learning at university: What the student does. 2011: McGrawHill Education (UK).

[18] Snelson, C., Teacher Video Production: Techniques for Educational YouTube Movies, in Society for Information Technology \& Teacher Education International Conference 2011, M. Koehler and P. Mishra, Editors. 2011, Association for the Advancement of Computing in Education (AACE): Nashville, Tennessee, USA. p. 1218-1223.

[19] Sturges, M. and J. Reyna. Use of Vimeo on-line video sharing services as a reflective tool in higher educational settings: A preliminary report. in ASCILITE-Australian Society for Computers in Learning in Tertiary Education Annual Conference. 2010.

[20] Spires, H. and G. Morris, New Media Literacies, Student Generated Content, and the YouTube Aesthetic, in EdMedia: World Conference on Educational Media and Technology 
2008, J. Luca and E.R. Weippl, Editors. 2008, Association for the Advancement of Computing in Education (AACE): Vienna, Austria. p. 4409-4418.

[21] Willey, K. and A. Gardner, Investigating the capacity of self and peer assessment activities to engage students and promote learning. European Journal of Engineering Education, 2010. 35(4): p. 429-443.

[22] Hanrahan, S.J. and G. Isaacs, Assessing self-and peer-assessment: The students' views. Higher education research and development, 2001. 20(1): p. 53-70.

[23] Hattie, J. and H. Timperley, The power of feedback. Review of educational research, 2007. 77(1): p. 81-112.

[24] Phillips, R., C. McNaught, and G. Kennedy, Evaluating e-learning: Guiding research and practice. 2012: Routledge. 